Short Communication

\title{
SENNA PLANT INDUCES DISRUPTION ON THE MITOCHONDRIA OF HYMENOLEPIS DIMINUTA
}

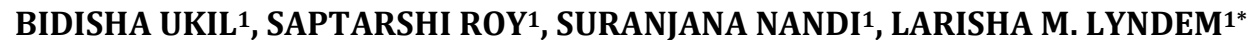

1Parasitology Research Laboratory, Department of Zoology, Visva-Bharati University, Santiniketan, West Bengal 731235

Email: lyndemlarisha@gmail.com

Received: 11 Aug 2017 Revised and Accepted: 29 Mar 2018

\begin{abstract}
Objective: The present study aims at observing the effects of three species of Senna plants, viz. Senna alata, S. alexandrina and S. occidentalis on the ultrastructure of the mitochondria of the tapeworm, Hymenolepis diminuta.
\end{abstract}

Methods: Worms were treated with leaf extracts of the three plant species with a standard dose concentration of $40 \mathrm{mg} / \mathrm{ml}$ and keeping one group of parasites in phosphate buffer saline (PBS) as a control. The parasites from control and treated medium were simultaneously removed after the loss of motility and fixed in 3\% gluteraldehyde. They were processed for ultramicrograph observations of the worm's mitochondria with special reference to shape and cytoplasm through transmission electron microscopy (TEM).

Results: The study showed loss of architecture in the outer mitochondrial membrane. The inner membrane became distorted with inconspicuous cristae and matrix became lucent in all plant treated worms compared to control. Amongst the three plants, S. alexandrina showed overall distortion in the shape leading to bloating of mitochondria.

Conclusion: The observations depict pronounced alterations in the structure of mitochondria, thus signifying depletion of energy synthesis in the parasite. Senna plant could, therefore, be a potent anthelmintic alternative.

Keywords: Mitochondria, Ultrastructure, Transmission Electron Microscopy, Senna

(C) 2018 The Authors. Published by Innovare Academic Sciences Pvt Ltd. This is an open access article under the CC BY license (http://creativecommons.org/licenses/by/4.0/) DOI: http://dx.doi.org/10.22159/ijpps.2018v10i5.25519

Helminthiasis is a major disease burden across the globe with severe infections causing malnutrition, malabsorbition, abdominal pain and cramping, poor cognitive and physical development in human being $[1,2]$. The degree and prevalence of infections vary with age, sex and the region of origin of the infection [3]. Anthelmintic drugs have been shown resistant by few helminth parasites which eventually led to a search for alternative medicines [4]. Plants with diverse medicinal properties became the prime focus of research [5]. Several plants have been used in designing and developing drugs for combating various infectious diseases.

Senna plant constitutes many species of shrubs and trees, most of which possess a rich source of secondary metabolites used for medicinal purposes and also for developing economically sound folklore remedies [6-8]. Three species of Senna plants viz. Senna alata Linn. Senna alexandrina Mill. and Senna occidentalis (L.) Link. (Leguminosae) possess medicinal activities including antidepressant, antianxiety and antimicrobial [9-11]. These plants showed anthelmintic efficacy on the tapeworm Hymenolepis diminuta through the tegument disruption [1214]. Alteration in the tegument architecture leads to an increase in the permeability of the membrane followed by an efflux of essential ions such as $\mathrm{Ca}^{2+}, \mathrm{Na}^{+}$and $\mathrm{K}^{+}$[15]. The gradual loss of ions due to membrane permeability is an important clue to the loss of bioactivity of the cell organelles. All cellular organelles serve their unique function due to which deprivation from their regular activities could possibly alter the metabolic backbone of the parasite. Hence the present study aimed at focussing on the morphology of the mitochondria being the power generating organelle.

The conventional description of mitochondrial structure derived from electron microscopic (EM) studies characterized mitochondria as spherical or short rod structures positioned in various parts of the cytoplasm [16]. The morphology of mitochondrial membranes and cristae also varies according to their functional status [17]. Tapeworm inhabiting vertebrate host's intestine are in dearth of oxygen but contain an abundance of mitochondria in some cells of $H$. diminuta. The latter are located mostly in the basal cytoplasm of the cuticular zone of the integument [18]. Such variation makes it not only an important aspect of parasite survival within the host body but also identifies it as a prime target for drug therapy.

Leaves of $S$. alata, S. alexandrina and S. occidentalis were collected from the University campus, as these plants are indigenous to this region. Each specimen has been identified in earlier studies and voucher specimen viz. VBSL-1, VBSL-2 and VBSL-3 for S. alata, S. occidentalis and S. alexandrina respectively, were accorded at Botanical Survey of India, Kolkata. The leaves were weighed and washed with distilled water and dried in the oven at $50{ }^{\circ} \mathrm{C}$. They were processed for leaf extract preparation in Soxhlet apparatus and the final crude extract was obtained through rotary evaporator following Kundu et al., 2012 [12]. The cestode parasite $H$. diminuta was used as an experimental model. It was maintained in the laboratory following the method adopted from Kundu et al., 2012 [12]. In brief, the gravid proglottids released by the parasites were collected from rat fecal samples and were fed to starving flour beetle (Tribolium sp.) for development of larval stage, the cysticercoids. The latter developed within the gut of the beetle after $10 \mathrm{~d}$ of infection and were later inoculated to adult male Sprague Dawley rat weighed150-200 grams for development of the adult parasites. $H$. diminuta were obtained from the intestine of the rat after $21 \mathrm{~d}$ of infection. All experiments with animals were approved by the Institutional Animal Ethics Committee (IAEC) of Visva-Bharati University (IAEC/VB/2017/06).

Rats were sacrificed and parasites were collected from the intestine in warm phosphate buffer saline (PBS). The worms were kept in plant extract medium containing standard $40 \mathrm{mg} / \mathrm{ml}$ concentration. of $S$. alata, $S$. alexandrina and $S$. occidentalis in $0.1 \mathrm{M}$ PBS with $1 \%$ dimethylsulfoxide (DMSO) [\{standardized concentration derived in earlier studies from our laboratory (11-13)\}]. One set of worms was kept as control with only PBS and DMSO. The parasites were removed from the treated medium after they lost their motility which was about $2 \mathrm{~h}$ (table 1). They were later washed in PBS and fixed in primary fixative i.e. $3 \%$ glutaraldehyde with two changes and then kept in the same fixative for 4-24 h. The worms were later washed in $0.1 \mathrm{M}$ cacodylate buffer and processed further for TEM study following standard method [19] and examined under JEOL JEM-100 CX-II electron microscope. 
Table 1: Effect of crude leaf extracts of Senna plants on Hymenolepis diminuta

\begin{tabular}{lll}
\hline Treatment $\mathbf{( 4 0} \mathbf{~ m g} / \mathbf{m l})$ & Paralysis (h) & Mortality (h) \\
\hline Senna alata & $1.68 \pm 0.06$ & $9.39 \pm 0.14$ \\
Senna alexandrina & $2.32 \pm 0.1$ & $16.65 \pm 0.3$ \\
Senna occidentalis & $3.86 \pm 0.1$ & $20.42 \pm 0.21$ \\
\hline
\end{tabular}

Each value presented as mean $\pm \mathrm{SD}(\mathrm{n}=6$ ); Control survived upto 69.22 $\pm 0.23 \mathrm{~h}$ (Cited from Kundu et al., 2012, 2015, 2016).

TEM micrographs showed circular mitochondria with the smooth architectural outer membrane. Prominent cristae were seen as infoldings in the inner membrane that extend to the sarcoplasm and dense matrix was observed in the control worms (fig. 1a). However, in all the plant treatments, mitochondria showed outer membrane disruption and lucent matrix with distorted inner membrane and inconspicuous cristae. S. alata showed overall distortion in the outer membrane of the mitochondria, cristae were displaced but the matrix remained dense as control (fig. 1b). While in S. alexandrina, both the outer and inner membrane of mitochondria were disrupted and the mitochondria became bloated or expanded. Loss of dense matrix in the sarcoplasm and instead became lucent with indistinguished cristae (fig. 1c). The worms treated with S. occidentalis showed roughness and wrinkle like formation in the outer membrane of the mitochondria with clumped cristae (fig. 1d). From all the three plants S. alexandrina showed high efficacy against $H$. diminuta with respect to alteration.
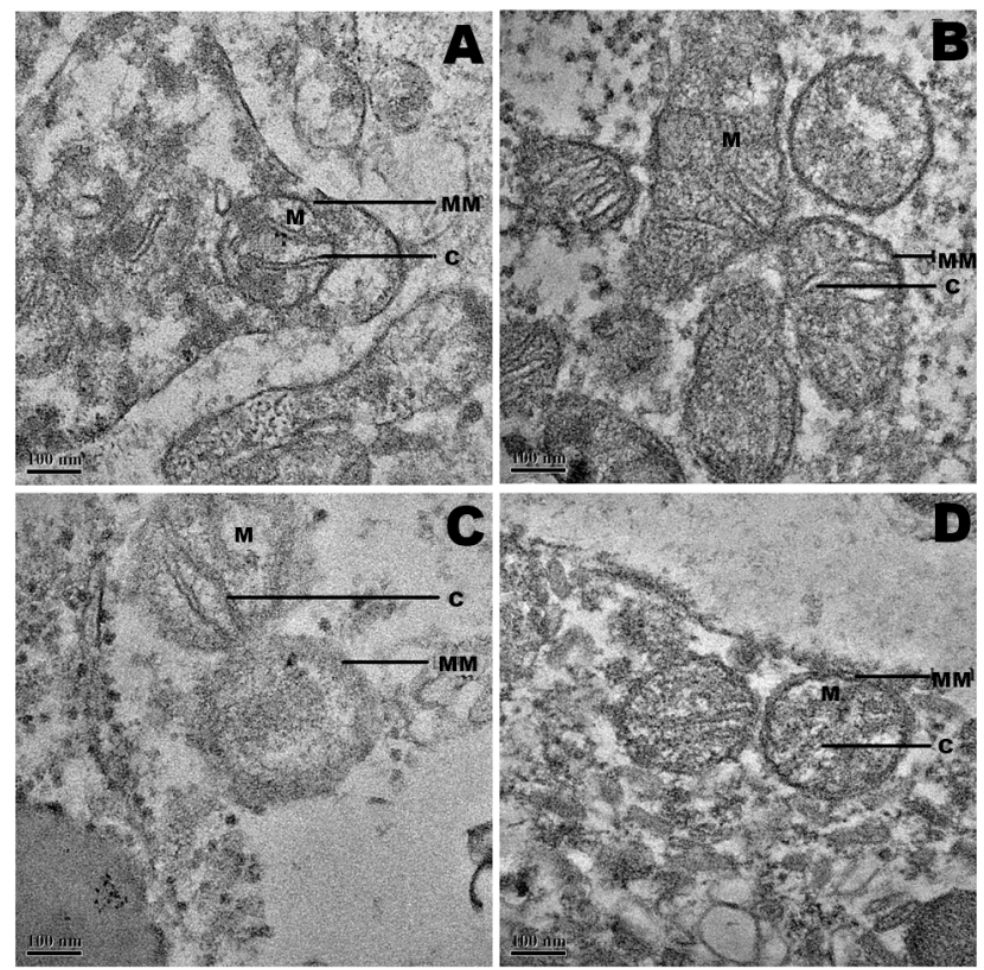

Fig. 1: TEM studies on the mitochondria of $H$. diminuta: A-Control: showing noticeable mitochondrial membrane (mm), dense matrix (m) and cristae (c); B-S. alata: indistinct mitochondrial membrane; C-S. alexandrina: showing lucent and indistinct membrane and cristae with transparent matrix; D-S. occodentalis: exhibiting a wrinkled membrane with alterations in the criatae and loss of density in the matrix

The present study revealed conspicuous ultrastructure deformities in the mitochondria treated with plant extracts with loss of outer and inner membrane architecture. Further, bloating of the mitochondria was also seen, which perhaps could lead to direct alterations in membrane permeability and potential. A similar observation was reported in mitochondria when exposed to chemical agents and phytochemicals $[20,21]$. The elongated conformation of cristae disappears in treated worms. Such observation was also seen in helminth parasites treated with plant products [22]. Distortion of the mitochondrial membrane with loss of cristae was observed in cestode and in trematode, when exposed to crude extracts and active plant compound $[23,24]$. This alteration may suggest an impediment in energy biosynthesis. Such alteration may have consequent changes in the electron transport system and activities of mitochondrial enzymes that remain mostly localized in the inner mitochondrial membrane and matrix [25]. The present study thus indicated that the plant possesses vermifugal or vermicidal activity.

\section{ACKNOWLEDGEMENT}

The authors thank the University Grants Commission, New Delhi, India for providing financial support to the first author (grant no: $\mathrm{F}$. No. 25-1/2014-15 (BSR)/5-132/2007/(BSR). Thanks are also extended to Sophisticated Analytical Instrument Facility, North Eastern Hill University, Shillong, India for providing laboratory support on TEM.

\section{AUTHORS CONTRIBUTIONS}

The work was planned by the corresponding author and execution of the work and manuscript preparation was done by the first author. The second author maintained the parasite model in our laboratory and the plant extracts were prepared by the third author.

\section{CONFLICT OF INTERESTS}

No potential conflict of interest was reported by the authors 


\section{REFERENCES}

1. Hotez PJ, Brindley PJ, Bethony JM, King CH, Pearce EJ, Jacobson J. Helminth infections: the neglected tropical diseases. J Clin Invest 2008;118:1311-21.

2. Samuel F, Demsew A, Alem Y, Y Hailesilassie. Soil-transmitted helminthiasis and associated risk factors among elementary school children in ambo town, western Ethiopia. BMC Public Health 2017;17:791.

3. Abu Madi MA, Behnke JM, Boughattas S, Al-Thani A, Doiphode $\mathrm{SH}$, Deshmukh A. Helminth infections among long-term residents and settled immigrants in Qatar in the decade from 2005 to 2014: temporal trends and varying prevalence among subjects from different regional origins. Parasit Vectors 2016;9:153.

4. Barakat R, Morshedy HE. Efficacy of two praziquantel treatments among primary school children in an area of high Schistosoma mansoni endemicity, Nile Delta, Egypt. Parasitology 2010;4:1-7.

5. Archana D, Dixitha M, Santhy KS. Antioxidant and anticlastogenic potential of Piper longum L. Int J Appl Pharm 2015;7:11-4.

6. Khare P, Kishore K, Sharma DK. A study on the standardization parameters of Cassia angustifolia. Asian J Pharm Clin Res 2017;10:329-32.

7. Wikaningtyas P, Sukandar EY. Evaluation of the combined antibacterial activity of Kaempferia pandurata rhizome and Senna alata leaves against methicillin-resistant Staphylococcus aureus. Asian J Pharm Clin Res 2016;9:112-4.

8. Harsha MN, Dulloo P, Rupachandra S, Jagadeeshwari S, Davina JM, Porkodi S. Isolation and identification of antimicrobial proteins from the leaves of Valeriana hardwickii and Senna obtusifolia. Asian J Pharm Clin Res 2018;11:438-40.

9. Pamulaparthi A, Prathap VR, Banala M, Nanna RS. Experimental evaluation of antidepressant and antianxiety activities of aqueous leaf extracts of Senna alata (l.) Roxb. using in vitro animal models. Int J Curr Pharm Res 2016;8:60-3.

10. Sermakkani M, Thangapandian V. GC-MS analysis of Cassia italica leaf methanol extract. Asian J Pharm Clin Res 2012;5:90-4.

11. Vyas A, Sarin R. Efficacy of leaf extracts of Cassia angustifolia (Linn.) for antimicrobial activity and phytochemical analysis. Int J Pharm Bio Sci 2013;4:(B)713-18.

12. Kundu S, Roy S, Lyndem LM. Cassia alata L: potential role as an anthelmintic agent against Hymenolepis diminuta. Parasitol Res 2012;111:1187-92.
13. Kundu S, Roy S, Nandi S, Ukil B, Lyndem LM. In vitro anthelmintic effects of Senna occidentalis (L.) Link (Leguminosae) on rat tapeworm Hymenolepis diminuta. In J Pharm Pharm Sci 2015;7:268-71.

14. Kundu S, Roy S, Nandi S, Ukil B, Lyndem LM. Senna alexandrina Mill. Induced ultrastructural changes on Hymenolepis diminuta. J Parasit Dis 2016;41:147-54.

15. Roy S, Kundu S, Lyndem LM. Senna leaf extracts induced $\mathrm{Ca}^{2+}$ homeostasis in a zoonotic tapeworm Hymenolepis diminuta. Pharm Biol 2016;54:2353-7.

16. McCarron JG, Wilson C, Sandison ME, Olson ML, Girkin JM, Saunter C, et al. From structure to function: Mitochondrial morphology, motion and shaping in vascular smooth muscle. J Vasc Res 2013;50:357-71.

17. Picard M, Gentil BJ, McManus MJ, White K, Louis KS, Gartside $\mathrm{SE}$, et al. Acute exercise remodels mitochondrial membrane interactions in mouse skeletal muscle. J Appl Physiol 2013;115:1562-71.

18. Lumsden RD. Ultrastructure of mitochondria in a cestode, Lacistorhynchus tenuis (V. Beneden, 1858). J Parasitol 1967;53:65-77.

19. Dykstra MJ, Reuss LE. Biological electron microscopy theory, techniques and troubleshooting. New York: Plenum Press; 1992.

20. Isaev NK, Zorov DB, Stemalshook EV, Uzbekov RE Kozhemyakin MB, Victor IV. Neurotoxic glutamate treatment of cultured cerebellar granule cells induces $\mathrm{Ca}^{2+}$-dependent collapse of mitochondrial membrane potential and ultrastructural alterations of mitochondria. FEBS Lett 1996;392:143-7.

21. Tari C, Fournier N, Briand C, Ducet G, Crevat A. Action of vinca alkaloids on calcium movements through mitochondrial membrane. Pharmacol Res Commun 1986;18:519-28.

22. Giri BR, Roy B. Resveratrol-induced structural and biochemical alterations in the tegument of Raillietina echinobothrida. Parasitol Int 2014;63:432-7.

23. Dasgupta S, Giri BR, Roy B. Ultrastructural observations on Raillietina echinobothrida exposed to crude extract and an active compound of Securinega virosa. Micron 2013;50:62-7.

24. Roy B, Swargiary A, Giri BR. Alpinia nigra (Family Zingiberaceae): an anthelmintic medicinal plant of north-east India. Adv Life Sci 2012;2:39-51.

25. Veerakumari L, Chitra N. Effect of Allium sativum on the carbohydrate metabolism of Haemonchus contortus. Int J Sci Res 2016;5:780-6. 